\title{
Evaluation of Malaria Blood Smears Sent to National Malaria Reference Laboratory
}

\author{
Doğrulama Laboratuvarına Gönderilen Sttma Kan Yaymalarının \\ Değerlendirilmesi
}

\author{
(1) Selma Usluca ${ }^{1}$, (1) Cahit Babur ${ }^{1}$, (1) Özlem Kurtcebe², (1) Seher Topluoğlu², (1) Selçuk Kılıç \\ ${ }^{1}$ General Directorate of Public Health, Department of Microbiology Reference Laboratories and Biological \\ Products, Ankara, Turkey \\ ${ }^{2}$ General Directorate of Public Health, Department of Zoonotic and Vector-borne Diseases, Ankara, Turkey
} Cite this article as: Usluca S, Babur C, Kurtcebe Ö, Topluoğlu S, Kilç̧ S. Evaluation of Malaria Blood Smears Sent to National
Malaria Reference Laboratory. Turkiye Parazitol Derg 2019;43(4):165-9.

\begin{abstract}
Objective: Although the disease has been eliminated in Turkey malaria continues to be a threat due to increase in the number of people coming from or going to countries where the disease is endemic. In this study, we aimed to evaluate blood smears sent to the National Malaria Reference Laboratory within the malaria surveillance system.

Methods: From March 2016 to July 2018 a retrospective study was conducted to compare the results of Malaria Reference Laboratory and Public Health Laboratories. A total of 16.827 blood stains were sent to our laboratory for approval.

Results: In Public Health Laboratories, 315 (1.88\%) of the smears were positive, 16.510 (98.12\%) were negative, and in the National Malaria Reference Laboratory 252 (1.50\%) were positive, 16.466 were negative. In the Public Health Laboratories, one of the two samples considered to be malaria suspected was positive in the National Malaria Reference Laboratory and one was negative. In Public Health Laboratories 35.88\% of smears were P. falciparum, 27.30\% were Plasmodium spp., 20.96\% were $P$. vivax, $14.92 \%$ were mixed infection, $0.63 \%$ were P. malariae, $0.31 \%$ were $P$. ovale, and in the Reference Laboratory $49.60 \%$ were Plasmodium spp., $29.37 \%$ were $P$. falciparum, $16.27 \%$ were $P$. vivax, $4.36 \%$ were mixed infection, $0.40 \%$ were $P$. malariae.

Conclusion: In order to malaria surveillance system to be maintained in a healthy manner, preparation, staining, coding, packaging, transportation of blood slides is very important. Also if necessary, continuing training of laboratory staff working in malaria diagnosis is crucial.
\end{abstract}

Keywords: Malaria, Plasmodium, surveillance, microscopy, public health

Öz

Amaç: Türkiye'de elimine edilmiş olmasına rağmen sıtma, hastalığın endemik olduğu ülkelerden gelen veya bu ülkelere giden insanların sayısındaki artış nedeniyle bir tehdit olmaya devam etmektedir. Bu çalışmada, sıtma sürveyans sistemi kapsamında Ulusal Sıtma Referans Laboratuvarı'na gönderilen kan yaymalarının değerlendirilmesi amaçlanmıştır.

Yöntemler: Mart 2016 ile Temmuz 2018 arasında Ulusal Sıtma Referans Laboratuvarı ve Halk Sağlığı Laboratuvar'larının sonuçlarını karşılaştırmak için retrospektif bir çalışma yapılmıştır. Laboratuvar’ımıza doğrulama için toplam 16,827 kan yayma örneği gönderilmiştir.

Bulgular: Halk Sağlığı Laboratuvarları́nda preparatların 315’i (\%1,88) pozitif, 16.510’u (\%98,12) negatif olarak değerlendirilirken, Ulusal Sitma Referans Laboratuvarı'nda 252'si (\%1,50) pozitif, 16.466’sı negatif olarak değerlendirildi. Halk Sağlığı Laboratuvarları'nda sıtma şüpheli olarak değerlendirilen iki örnekten biri Ulusal Sitma Referans Laboratuvarı'nda pozitif, biri ise negatif olarak değerlendirildi. Halk Sağlığ Laboratuvarları'nda pozitif olarak belirlenen preparatlardan \%35,88'i P. falciparum, \%27,30'u Plasmodium spp., \%20,96's1 P. vivax, \%14,92'si miks enfeksiyon, \%0,63'ü P. malariae, \%0,31'i P. ovale olarak belirlenirken, Referans Laboratuvarda \%49,60'1 Plasmodium spp., \%29,37'si P. falciparum, \%16,27'si P. vivax, \%4,36's1 miks enfeksiyon, \%0,40' $P$. malariae olarak belirlendi.

Sonuç: Sıtma surveyans sisteminin sağlıklı bir şekilde yürütülebilmesi için kan yaymalarının hazırlanması, boyanması, kodlanması, paketlenmesi, taşınması çok önemlidir. Ayrıca gerektiğinde sıtma tanısı koyan laboratuvar personelinin eğitimi çok önemlidir. Anahtar Kelimeler: Sitma, Plasmodium, surveyans, mikroskopi, halk sağlığı 


\section{INTRODUCTION}

Turkey is located in the middle of the land called the World Island, consisting of Asia, Europe and Africa, and in the subtropical zone near Caucasia, Balkans and Middle East. Malaria has been one of the most significant diseases in Anatolian history where Plasmodium vivax (P. vivax), Plasmodium malariae (P. malariae) and Plasmodium falciparum ( $P$. falciparum) were the causative agents of autochthonous transmission (1). Malaria has been a notifiable disease since 1930 and all the health institutions are required to report all the malaria cases (2). In 1946, the Directorate of Malaria Control was set up under the Ministry of Health and Social Assistance (3). Turkey, active surveillance founded in 1957 by launching the National Malaria Eradication Program, and this led to the 1970 control of infection (1). Active case detection through house-to-house visits by sanitarians (every two weeks during the transmission season and once a month at other times) included within the surveillance system. Every clinical malaria case is confirmed by testing in quality-controlled laboratories, supervised by a national Reference Laboratory (3). In 1983 the eradication program was replaced with a "Malaria Control Program". After the implementation of this program the highest number of cases with malaria was reported as 84.345 in 1994. After 1995, the number of malaria cases showed a regular decline down to 10.224 in 2002 (1). Turkish Ministry of Health launched a big-scale health policy entitled "Health Transformation Program" in 2003 , with an aim to supply more efficient and higher quality health services. With regards to the planning and delivery of these services, the priority has been given to the preventive means, Primary Health Care Services has been strengthened and on issues like proper functioning of Public Health Services and the efficient control of epidemic diseases has been focused. After the establishment of Health Transformation Program, the number of malaria cases has been on regular decline after 2003, down to 796 in 2006. Consequently, considering that the optimum conditions for malaria eradication have been achieved in Turkey, Tashkent Declaration was signed and approved by the Ministry of Health in 2006 and the current program was changed to "Malaria Elimination Program of Turkey" (1). The Malaria Elimination Program adopted a comprehensive and integrated approach, directing interventions to the main components of the epidemiological process-source of infection, mode of transmission and receptive population. Turkey's strong political commitment was backed up by the necessary operational and technical capacity to achieve interruption of transmission and maintain results (3). Turkey has eliminated the disease but malaria continues to be a threat due to increase in numbers of the people coming from or going to the countries where the disease is endemic and increased risk of expansion of vector habitats as a result of climate change which may make the conditions favorable for reintroduction of local malaria transmission. Primary laboratory diagnosis of malaria is conducted at all clinical laboratories at governmental and private hospitals and outpatient clinics as well as at the Public Health Laboratories. Every clinical malaria case is confirmed by testing in quality-controlled laboratories, supervised by a National Reference Laboratory. Laboratory quality assurance and control is carried out by L1 type Public Health Laboratories and by National Malaria Reference Laboratory. Evaluated blood samples by L2 type Public Health Laboratories send all positives and 20\% of negative ones to L1 type Public Health Laboratories. L1 type Public Health Laboratories, on the other hand, send all positive slides and $20 \%$ of those which were evaluated as negative in L2 type Public Health Laboratories to the National Malaria Reference Laboratory for confirmation (4). Since 2012, the National Malaria Reference Laboratory, Microbiology Reference Laboratories Department of the Turkish Public Health Institute has been used as a national reference laboratory, re-confirming positive smears and examining $20 \%$ of the negative smears already cross-checked in the control laboratories (3).

In this study, we aimed to evaluate blood smears sent to the National Malaria Reference Laboratory within the malaria surveillance system.

\section{METHODS}

After blood samples are collected by active and passive surveillance, they are evaluated by L2 type Public Health Laboratories and all positives and $20 \%$ of negative ones are sent to L1 type Public Health Laboratory. L1 type Public Health Laboratories, on the other hand, send all positive slides and $20 \%$ of those which were evaluated as negative in L2 type Public Health Laboratories to the National Malaria Reference Laboratory for confirmation.

In this retrospective study malaria test results of Provincial Public Health Laboratories and National Malaria Reference Laboratory in Turkey from March 2016 to July 2018 were analyzed. The records of National Malaria Reference Laboratory evaluated by means of compliance with the Provincial Public Health Laboratories results. Excel file was used to evaluate the data of the samples. This study follows the principles of the Declaration of Helsinki.

\section{RESULTS}

Of the 16.827 blood smears, 20 smears sent to our laboratory for confirmation between March 2016 and July 2018 were found to be broken which made the evaluation impossible and it was found that $97(0.58 \%)$ smears did not reach our laboratory despite being included in the sent lists. When monthly dispatches were evaluated, it was determined that 13 of the 17 provinces (76.47\%) regularly send and 4 provinces (23.53\%) irregularly send the blood slides. It was determined that 7 (53.85\%) of the dispatched provinces did not encode the smears as determined or that there were differences between smears and list's codes and 6 of them $(46.15 \%)$ coded as determined. The results of evaluation of laboratories are given in Table 1. In Public Health Laboratories, 315 (1.88\%) of the smears were positive, 16.510 (98.12\%) were negative, and in the National Malaria Reference Laboratory $252(1.50 \%)$ were positive, 16.466 were negative. In the Public

\begin{tabular}{|c|c|c|c|}
\hline & $\begin{array}{l}\text { Number } \\
\text { of positive } \\
\text { smears }\end{array}$ & $\begin{array}{l}\text { Number of } \\
\text { negative } \\
\text { smears }\end{array}$ & Total \\
\hline $\begin{array}{l}\text { Provincial } \\
\text { laboratories (Public } \\
\text { Health Laboratories) }\end{array}$ & 315 (1.88\%) & $16.510(98.12 \%)$ & $16.825^{a}$ \\
\hline $\begin{array}{l}\text { National Malaria } \\
\text { Reference } \\
\text { Laboratory }\end{array}$ & 252 (1.50\%) & $16.466(97.85 \%)$ & $16.827^{b}$ \\
\hline \multicolumn{4}{|c|}{$\begin{array}{l}\text { aTwo smears were evaluated as suspicious in the province (one was positive } \\
\text { in the Reference Laboratory and the other was negative), '109 smears were } \\
\text { considered incomplete in Reference Laboratory due to inappropriate slide } \\
\text { preparation (97) and broken smears (12) }\end{array}$} \\
\hline
\end{tabular}


Health Laboratories, one of the two samples considered to be malaria suspected was positive in the National Malaria Reference Laboratory and one was negative. Parasite species-level results of the smears that are considered as positive are given in Table 2. In Public Health Laboratories $35.88 \%$ of smears were P. falciparum, $27.30 \%$ were Plasmodium spp., $20.96 \%$ were $P$. vivax, $14.92 \%$ were mixed infection, $0.63 \%$ were P. malariae, $0.31 \%$ were $P$. ovale, and in the Reference Laboratory $49.60 \%$ were Plasmodium spp., $29.37 \%$ were $P$. falciparum, $16.27 \%$ were $P$. vivax, $4.36 \%$ were mixed infection, $0.40 \%$ were $P$. malariae. Compliance of the evaluation results of the laboratories is indicated in Table 3.

\section{DISCUSSION}

Besides irrigated agriculture, resistances to anti-malarial drugs and to insecticides are some of the other factors that might affect the pattern of malaria prevalence rates (5). One of the factors contributing to the reemergence of malaria is human migration. People move for a number of reasons, including environmental deterioration, economic necessity, conflicts, and natural disasters. Identifying and understanding the influence of these population movements can improve prevention measures and malaria control programs (6). Turkey has a high risk of malaria transmission because of increasing internal and external population mobility (5). History shows that an increase in migration from neighbouring countries may cause a rise in malaria importation. It is important to consider the effect that continuing political instability in the Syrian Arab Republic may have on malaria status in Turkey. Maintaining epidemiological surveillance of malaria to ensure prompt detection and treatment of cases, as well as a timely response to any emergency, will also be important (3). Robust and responsive surveillance systems are critical for elimination of malaria. In countries pursuing malaria elimination, when the number of incidences is low enough, rapid reporting of cases should be implemented (7). Most malaria

Table 2. Laboratories results according to Plasmodium species

\begin{tabular}{|l|l|l|}
\hline & $\begin{array}{l}\text { Provincial } \\
\text { laboratories }\end{array}$ & $\begin{array}{l}\text { National Malaria } \\
\text { Reference Laboratory }\end{array}$ \\
\hline P. falciparum & $113(35.88 \%)$ & $74(29.37 \%)$ \\
\hline P. vivax & $66(20.96 \%)$ & $41(16.27 \%)$ \\
\hline P. ovale & $1(0.31 \%)$ & 0 \\
\hline P. malariae & $2(0.63 \%)$ & $1(0.40 \%)$ \\
\hline P. knowlesi & 0 & 0 \\
\hline Mixed infection & $47(14.92 \%)$ & $11(4.36 \%)$ \\
\hline Plasmodium spp. & $86(27.30 \%)$ & $125(49.60 \%)$ \\
\hline Total & 315 & 252 \\
\hline
\end{tabular}

control programs have passive surveillance systems to identify, treat, and report individuals who present themselves to health facilities. The passive case detection only detects symptomatic patients and overlook individuals who are not seeking treatment. On the contrary, active surveillance which involves screening of population by visiting door to door, targeting of all subjects with fever or history of fever is suitable for difficult and hard-to-reach areas in an attempt to increase access to care in underserved areas. In a study of India, by active case detection and passive case detection in the Baihar Public Health Center villages, microscopic examination of blood smears and malaria parasite rates were determined. Comparison of results of the two methods revealed that active case detection in villages provided a relatively large number of malaria positive cases compared to passive case detection in Public Health Center villages. The population that is not visiting health facilities is inseminated to surrounding population in receiving regions, thus creating new foci. By treating these individuals, it not only protects the society but has also leads to a significant reduction in transmission density (8). In our country, passive and active surveillance is carried out together, especially the importance of active surveillance studies in controlling malaria is understood when the course of the disease is evaluated over the years.

In a study of Bhutan, of the 2.514 blood smears assessed, it was decided by the Vector-borne Disease Control Program official that 1.160 (46.14\%) was of excellent quality (defined as any stain or stain-free problem and containing both thick and thin films). More than half of the blood smears were optimally evaluated at least in one feature. The biggest problem was that only $56 \%$ of smears were prepared with both thick and thin smears (38\% had only a thick smear). The fact that the number of blood smears sent for verification is lower than expected may suggest that there is no admissibility in this part of the process. Other deficits were less common (91\% normal size, $88 \%$ equal and $93 \%$ satisfactorily stained). Sixty smears (2.4\%) were broken in Vector-borne Disease Control Program and could not be evaluate for cross control (9). In our study, of the 16.827 smears, 12 smears sent to our laboratory for confirmation were found to be broken which made the evaluation impossible and it was found that 97 smears did not reach our laboratory despite being included in the sent lists. It was determined that seven (53.85\%) of the dispatched provinces did not encode the smears as determined or that there were differences between smears and list's codes, and six of them (46.15\%) coded as determined.

In a study of Indonesia, in passive surveillance, the collected thick and thin blood smears from suspected cases of malaria was immediately examined by experienced microscopists. Quality assurance was performed by a regional specialist certified microscope and $10 \%$ of randomly selected negatives for all positive

Table 3. Compliance of evaluation results of the laboratories

\begin{tabular}{|l|l|l|l|l|}
\hline \multirow{4}{*}{ Provincial laboratories } & \multicolumn{2}{|l|}{ National Malaria Reference Laboratory } \\
\cline { 2 - 5 } & & $\begin{array}{l}\text { Number of positive } \\
\text { smears }\end{array}$ & $\begin{array}{l}\text { Number of negative } \\
\text { smears }\end{array}$ & Total \\
\cline { 2 - 5 } & Number of positive smears & $243(77.64 \%)$ & $70(22.36 \%)$ & $313(1.88 \%)$ \\
\cline { 2 - 5 } & Number of negative smears & $8(0.05 \%)$ & $16.397(99.95 \%)$ & $16.405(98.12 \%)$ \\
\cline { 2 - 5 } & Total & $251(1.50 \%)$ & $16.467(98.50 \%)$ & $16.718^{a}$ \\
\hline a109 smears were considered incomplete in Reference Laboratory due to inappropriate slide preparation (97) and broken smears (12) \\
\hline
\end{tabular}


cases. For all positive cases, more cross-control was performed at provincial level, and inconsistent results were resolved between Primary Health Care and district-level microscopists. Laboratory test results 41 of 42 record-positive malaria cases reported in passive surveillance were confirmed positively in the second evaluating (16 P. vivax, 20 P. falciparum, 2 P. knowlesi and 3 P. malariae). In reactive case detection, 1.495 were tested positive by microscopy ( 1 P. vivax and 2 P. falciparum). A total of 43 cases of malaria were identified, which combined passive and active surveillance data. Of these, 15 (34.9\%) were P. vivax, 8 (18.6\%) were $P$. falciparum and 20 (46.5\%) were Plasmodium knowlesi ( $P$. knowlesi). As a note, $P$. knowlesi infections were misdiagnosed as 10 P. falciparum, seven $P$. vivax, one $P$. malariae and two unclear by microscopy (10). A total of 3.004 blood smears were evaluated in the study comparing the effectiveness of the microscopy of the laboratory in the field and the central laboratory in the malaria active surveillance program in Western Thailand. In the absence of parasites in at least 50-100 areas in the field laboratory, the first thin film was considered negative and each smear was evaluated for approximately five minutes. Subsequently, all blood smears were evaluated by an experienced microscopist for 20 minutes and first thin film was considered negative when no parasites were detected in at least 100 areas. All smears with incompatible results and $20 \%$ of smears with compatible results were checked by a different expert. It was determined that $5.2 \%$ of the samples examined by experienced microscopist were P. falciparum, $5.9 \%$ were $P$. vivax and $0.1 \%$ were both mixed infection. It has been reported that $84.4 \%$ of $P$. falciparum positive smears and $93.9 \%$ of $P$. vivax positive smears have a parasitemia rate of less than $500 /$ $\mu \mathrm{L}$. The specificity of the field microscopy for P. falciparum positive smears was $99.3 \%$, the sensitivity was $10.0 \%$, the specificity for $P$. vivax positive smears was $38.7 \%$ and the sensitivity was 93.9\%. It was reported that field microscopy was not an effective method for active malaria surveillance in Western Thailand, where prevalence and parasitemia rates were low (11). When the literature is evaluated, it is seen that problems faced by the surveillance system are smilar in many countries. In our study, in L2 laboratories, $1.88 \%$ of blood smears were evaluated as positive and $98.12 \%$ of them were evaluated as negative while $1.50 \%$ of the blood smears were found out to be positive and $97.85 \%$ were found out to be negative in Reference Laboratory. Two smears were evaluated as suspicious in the province (one was positive in the Reference Laboratory and the other was negative). It was determined that Public Health Laboratories evaluated $0.25 \%$ of smears as false negative. One possible reason for this may be the inadequate preparation quality. Sufficient blood samples should be used when preparing the smear. The use of a small amount of blood sample may cause the diagnosis to be missed out in patients with low parasitemia and homogeneous spread of the preparation is not possible. In the same way, it is not possible to blood smear preparation homogeneously in case of excessive blood samples and microscopic evaluation cannot be made precisely because the blood cells overlap and diagnosis can be omitted. The second important issue may be lack of adequate staining quality of the smear. It is necessary to prepare the Giemsa stain fresh each time, to prepare stain appropriately, to apply staining times appropriately, to stain the amount and manner to completely cover each preparation, to wash smear without damaging and to remove the excess stain. If Giemsa stain is not freshly prepared, stain precipitate may cause artifacts and may cause false positive results. The third important issue is that the patient has been treated, has a low rate of parasitemia, has mixed infection. In the case of a low parasitemia rate, there may be false negativity, or diagnosis of minor species may be missed, especially in case of mixed infection. Microscopic diagnosis becomes more difficult in treated patients because of the disturbed morphological structure of the parasite. The type of pathogen is another important issue affecting the outcome. For example, the rate of parasitemia is high in malaria cases caused by $P$. falciparum, while the rate of parasitemia is low in malaria cases caused by $P$. vivax. Finally, the lack of experience of microscopist evaluating smear and lack of sufficient time to evaluate smears due to workload of laboratory are among the reasons for discordant results.

In a study carried out in Iranshahr, one of the most important malaria endemic regions of Iran, information such as smear size, staining quality, quality of microscope and type of microscope were collected by 3.783 Giemsa stained smears collected in field diagnostic laboratories. All preparations were then re-examined by an experienced microscopist and the results were compared. $91.7 \%$ of smears are thick film and $8.3 \%$ are thin smears. According to staining quality, $34 \%$ of smears were good, $39.2 \%$ were medium and $26.8 \%$ were low quality. As a result of evaluation of microscopist in the field, it was determined that $73.2 \%$ of 295 smears were $P$. vivax, $26.4 \%$ were $P$. falciparum, $0.4 \%$ were mixed infection, and $72.7 \%$ of 315 positive smears were $P$. vivax, $26.4 \%$ were positive. P. falciparum was found to be $1 \%$ mixed infection. The results of this study showed that $99 \%$ of the diagnosis of malaria in the field was perfectly diagnosed. This high quality of malaria diagnosis in Iranshahr was thought to be related to the experience of microscopists and effective training programs, and the impact of educational strategies on improving malaria diagnosis was demonstrated (12). In order to support microscopic diagnosis, the National Malaria Reference Laboratory provides theoretical and practical training for the diagnosis of malaria for employees of the Public Health Laboratory in 81 provinces. However, due to frequent displacement of these staff, need for experienced staff remains.

In our study of blood smears evaluated; $35.88 \%$ were $P$. falciparum, $20.96 \%$ P. vivax, $0.31 \%$ Plasmodium ovale, $0.63 \%$ P. malariae, $14.92 \%$ mixed infection, $27.30 \%$ Plasmodium spp. has been determined by L2 laboratories. The results of re-evaluation of these blood smears in the Reference Laboratory are as follows: $29.37 \%$ P. falciparum, $16.27 \%$ P. vivax, $0.40 \%$ P. malariae, $4.36 \%$ mixed infection and $49.60 \%$ of Plasmodium spp. In the Reference Laboratory, some of smears could only be diagnosed at genus level and no identification could be made at species level. This is due to the fact that some of the smears were broken in such a way that they could not be examined adequately during dispatch from Public Health Laboratories to the National Malaria Reference Laboratory, that some smears were not prepared with adequate quality, they were not stained or that some smears were prepared as thick film which did not allow diagnosis at species level, thin smears have not been sent. When the evaluation results of both laboratories were compared, it was revealed that there were differences between the differentiation rates of all Plasmodium species. We found that the blood smear cross-check assessment revealed a lack of diagnostic accuracy and demonstrated the need to take remedial measures. Since discrepancies between the results may be the source of new infections, it is thought that training of the Provincial Public Health Laboratory personnel 
in terms of microscopic evaluation should be updated. In our country, malaria surveillance system is performed only in the form of microscopic evaluation of blood smear preparations. Public Health Laboratories send the blood sample taken from the patient to the National Malaria Reference Laboratory for verification purposes separately from the surveillance system in order to avoid the diagnosis to be missed in suspicious cases. Microscopy, rapid diagnostic test and molecular tests are applied together by the Reference Laboratory and the patient results are given. Although there is a difference between the evaluation results of Public Health Laboratories and National Malaria Reference Laboratory, the diagnosis is not missed. However, even if the Reference Laboratory has performed the laboratory validation of that patient, since the patient's blood smear evaluation is blinded, it is given its results on the surveillance system only according to microscopic evaluation.

Compared with polymerase chain reaction, the sensitivity of microscopy and rapid diagnosis test for malaria diagnosis was reported as $75 \%$ (13). For this reason, it is important to give rutin patient results by using three methods together in our laboratory.

\section{CONCLUSION}

Probability of incorrect result is reduced by combination of more than one method in routine diagnosis of malaria. But as microscobic diagnosis is the only method used at provincial level experience of microscopist is very important. In order to malaria surveillance system to be maintained in a healthy manner, preparation, staining, coding, packaging and transportation of blood slides is very important and if necessary, continuing training of laboratory staff working in malaria diagnosis is crucial.

\section{* Ethics}

Ethics Committee Approval: Ethics committee approval was not received.

Informed Consent: Patient consent was not obtained.

Peer-review: Externally and internally peer-reviewed.

\section{* Authorship Contributions}

Concept: S.U., C.B., O.K., S.T., S.K., Design: S.U., C.B., O.K., S.T., S.K., Data Collection or Processing: S.U., Analysis or Interpretation: S.U., Literature Search: S.U., C.B., O.K., S.T., S.K., Writing: S.U., S.T.

Conflict of Interest: No conflict of interest was declared by the authors.

Financial Disclosure: The authors declared that this study received no financial support.

\section{REFERENCES}

1. Ozbilgin A, Topluoglu S, Es S, Islek E, Mollahaliloglu S, Erkoc Y. Malaria in Turkey: successful control and strategies for achieving elimination. Acta Trop 2011;120:15-23.

2. Umumi Hifzısihha Kanunu - Public Hygiene Law number: 1593. accepted on 24/24/1930. URL: http://www.mevzuat.gov.tr/ MevzuatMetin/1.3.1593.pdf [Accessed 03 April 2019].

3. World Health Organization, Eliminating malaria case-study 5, the long road to malaria elimination in Turkey.2013;1-79.URL: https://apps. who.int/iris/bitstream/handle/10665/94961/9789241506403_eng. pdf;jsessionid=C5E98B6064B31FE6090E661EA2E4D987? sequence $=1$ [Accessed 03 April 2019].

4. Circular on the Execution of Malaria Disease Management Services, number 2016/2, Ministry of Health. URL: https://kms.kaysis.gov.tr/ Home/Goster/128894?AspxAutoDetectCookieSupport=1 [Accessed 03 April 2019].

5. Piyal B, Akdur R, Ocaktan E, Yozgatligil C. An analysis of the prevalence of malaria in Turkey over the last 85 years. Pathog Glob Health 2013;107:304.

6. Martens P, Hall L. Malaria on the move: human population movement and malaria transmission. Emerg Infect Dis 2000;6:103-9.

7. Ohrt C, Roberts KW, Sturrock HJW, Wegbreit J, Lee BY, Gosling RD. Information systems to support surveillance for malaria elimination. Am J Trop Med Hyg 2015;93:145-52.

8. Singh N, Bharti PK, Kumre NS. Active v. passive surveillance for malaria in remote tribal belt of Central India: implications for malaria elimination. Pathog Glob Health 2016;110:178-84.

9. West N, Gyeltshen S, Dukpa S, Khoshnood K, Tashi S, Durante A, et al. An evaluation of the National Malaria Surveillance System of Bhutan, 2006-2012 as it approaches the goal of malaria elimination. Front Public Health 2016;4:1-10.

10. Herdiana H, Cotter C, Coutrier FN, Zarlinda I, Zelman BW, Tirta YK, et al. Malaria risk factor assessment using active and passive surveillance data from Aceh Besar, Indonesia, a low endemic, malaria elimination setting with Plasmodium knowlesi, Plasmodium vivax, and Plasmodium falciparum. Malar J 2016;15;468:1-15.

11. Coleman RE, Maneechai N, Rachaphaew N, Kumpitak C, Miller RS, Soyseng V, et al. Comparison of field and expert laboratory microscopy for active surveillance for asymptomatic Plasmodium falciparum and Plasmodium vivax in Western Thailand. Am J Trop Med Hyg 2002;67:1414.

12. Darania HY, Ranjbarb M, Saidzadehc SA, Manouchehria K, Shahbakhshd $\mathrm{N}$, Aminifarde M. The quality of feld malaria diagnosis in Iranshahr, Iran. J Vect Borne Dis 2005;42:74-6.

13. Jayasingh A, Rompicherla V, Nandagopal Radha RK, Shanmugam P. Comparative study of peripheral blood smear, rapid antigen detection, ELISA and PCR methods for diagnosis of malaria in a tertiary care centre. J Clin Diagn Res 2019;13:8-11. 